\title{
Phase equilibria in the quasiternary system $\mathrm{Cu}_{2} \mathrm{Se}-\mathrm{SnSe}_{2}-\mathrm{Sb}_{2} \mathrm{Se}_{3}$
}

\author{
T.A. OSTAPYUK ${ }^{1 *}$, I.M. YERMIYCHUK ${ }^{1}$, O.F. ZMIY ${ }^{1}$, I.D. OLEKSEYUK ${ }^{1}$ \\ ${ }^{1}$ Department of General and Inorganic Chemistry, Lesya Ukrainka Volyn National University, \\ Voli Ave 13, 43009 Lutsk, Ukraine \\ *Corresponding author.E-mail: taras-ostapjuk@rambler.ru
}

Received July 6, 2009; accepted December 23, 2009; available on-line April 27, 2010

The isothermal section at $620 \mathrm{~K}$, the liquidus projection and six polythermal sections of the phase diagram of the system $\mathrm{Cu}_{2} \mathrm{Se}-\mathrm{SnSe}_{2}-\mathrm{Sb}_{2} \mathrm{Se}_{3}$ were constructed based on $\mathrm{X}$-ray diffraction, microstructure analysis and differential thermal analysis. The coordinates of the invariable points were determined. No quaternary or new ternary phases were observed in the system. The solid solutions based on the compound $\mathrm{Cu}_{2} \mathrm{SnSe}_{3}$ did not exceed $2 \%$.

Isothermal section / Polythermal section / Selenides

\section{Фазові рівноваги у квазіпотрійній системі $\mathrm{Cu}_{2} \mathrm{Se}-\mathrm{SnSe}_{2}-\mathrm{Sb}_{2} \mathrm{Se}_{3}$}

\author{
Т.А. ОСТАП’ЮК ${ }^{1}$ *, І.М. ЄРМІЙЧУК ${ }^{1}$, О.Ф. ЗМІЙ ${ }^{1}$, І.Д. ОЛЕКСЕЮК ${ }^{1}$ \\ ${ }^{1}$ Кафедра загальної та неорганічної хімії, Волинський національний університет імені Лесі Украӥнки, \\ пр. Волі 13, 43009 Луиььк, Україна \\ * Контактна особа. E-mail: taras-ostapjuk@rambler.ru
}

За допомогою рентгенофазового, мікроструктурного та диференціального термічного методів аналізу побудовано ізотермічний переріз при $620 \mathrm{~K}$, проекцію поверхні ліквідусу та шість політермічних перерізів системи $\mathrm{Cu}_{2} \mathrm{Se}-\mathrm{SnSe}_{2}-\mathrm{Sb}_{2} \mathrm{Se}_{3}$. Встановлено координати нонваріантних точок. Тетрарних $\mathrm{i}$ нових тернарних фаз у системі не виявлено. Протяжність твердих розчинів на основі сполуки $\mathrm{Cu}_{2} \mathrm{SnSe}_{3}$ не перевищус $2 \%$.

Ізотермічний переріз / Політермічний переріз / Селеніди

\section{1. Вступ}

Бінарні сполуки $\mathrm{Cu}_{2} \mathrm{Se}, \mathrm{Sb}_{2} \mathrm{Se}_{3}$ та $\mathrm{SnSe}_{2}$ мають конгруентний характер плавлення, при температурах 1421 К [1], 863 К [2] та 948 К [3] відповідно, і можуть бути вихідними компонентами квазіпотрійної системи. Система $\mathrm{Cu}_{2} \mathrm{Se}-\mathrm{SnSe}_{2}$ досліджувалась у роботах [4-6]. Знайдено одну сполуку $\mathrm{Cu}_{2} \mathrm{SnSe}_{3}$, що має конгруентний характер плавлення та утворюється при співвідношенні $\mathrm{Cu}_{2} \mathrm{Se}$ i $\mathrm{SnSe}_{2}$ 1:1. Система $\mathrm{Cu}_{2} \mathrm{Se}-\mathrm{Sb}_{2} \mathrm{Se}_{3}$ характеризується утворенням двох проміжних сполук - $\mathrm{CuSbSe}_{2} 3$ конгруентним характером плавлення при $765 \mathrm{~K}$ та $\mathrm{Cu}_{3} \mathrm{SbSe}_{3} 3$ інконгруентним характером плавлення при 808 K $[7,8]$. На основі високотемпературної модифікації $\mathrm{Cu}_{2} \mathrm{Se}$ та $\mathrm{Sb}_{2} \mathrm{Se}_{3}$ утворюються обмежені тверді розчини, які нижче температури $620 \mathrm{~K}$ мають незначну протяжність. Система $\mathrm{SnSe}_{2}-\mathrm{Sb}_{2} \mathrm{Se}_{3}$ раніше не досліджувалась.

\section{2. Методика експерименту}

Для встановлення взаємодій між компонентами у квазіпотрійній системі $\mathrm{Cu}_{2} \mathrm{Se}-\mathrm{SnSe}_{2}-\mathrm{Sb}_{2} \mathrm{Se}_{3}$ синтезовано 89 зразків. Усі зразки виготовлялися 3 високочистих простих речовин ( $\mathrm{Se}-99,999$ мас.\%; $\mathrm{Sn}$ - 99,999 мас.\%; $\mathrm{Cu}$ - 99,99 мас.\%; $\mathrm{Sb}-$ 99,99 мас.\%). Синтез здійснювався прямим однотемпературним методом, у кварцових вакуумованих ампулах. Максимальна температура синтезу - 1370 К. Гомогенізуючий відпал здійснювався при 620 К впродовж 600 годин. Зразки гартувалися у воді кімнатної температури. 
Усі зразки досліджувалися рентгенофазовим, диференціальним термічним і мікроструктурним методами аналізу.

Рентгенофазовий аналіз зразків проводився методом порошкової дифракції на дифрактометрі ДРОН-4-13 3 використанням $\mathrm{CuK}_{\alpha}$ випромінювання, діапазон сканування $10^{\circ} \leq 2 \theta \leq 90^{\circ}$, крок сканування $0,05^{\circ}$, час експозиції 2 с. Фазовий аналіз проводився 3 використанням пакетів програм DRWin та PowderCell.

Диференціальний термічний аналіз здійснювався на дериватографі Paulik-Paulik-Erdey 3 використанням $\mathrm{Pt} / \mathrm{Pt}-\mathrm{Rh}$ термопари та двокоординатного самописця Н307/1. Швидкість нагріву зразків становила $10 \mathrm{~K} / \mathrm{xв}$; охолодження проводилося в режимі виключеної пічки.

Межі існування твердих розчинів на основі сполуки $\mathrm{Cu}_{2} \mathrm{SnSe}_{3}$ уточнювались за допомогою мікроструктурного аналізу 3 використанням твердоміра Leica VMHTAuto.

\section{3. Результати експерименту та обговорення}

\section{1. Система $\mathrm{SnSe}_{2}-\mathrm{Sb}_{2} \mathrm{Se}_{3}$}

Для дослідження синтезовано 11 зразків. Встановлено, що ця система $\epsilon$ евтектичного типу 3 координатами евтектичної точки 50 мол.\% $\mathrm{Sb}_{2} \mathrm{Se}_{3}$, $\mathrm{T}_{\mathrm{E}}=773$ К (Рис. 1).

\section{2. Переріз $\mathrm{Cu}_{2} \mathrm{SnSe}_{3}-\mathrm{Sb}_{2} \mathrm{Se}_{3}$}

Переріз досліджувався на 15 зразках, синтезованих описаним вище методом. За результатами дослідження побудовано діаграму фазових рівноваг системи $\mathrm{Cu}_{2} \mathrm{SnSe}_{3}-\mathrm{Sb}_{2} \mathrm{Se}_{3}$ (Рис. 2). Як видно 3 рисунку, вона $\epsilon$ евтектичного типу 3 незначною взаємною розчинністю (не більше 2\%) вихідних компонентів. Координати евтектичної точки - 72 мол.\% $\mathrm{Sb}_{2} \mathrm{Se}_{3} . \mathrm{T}_{\mathrm{E}}=769$ К. Для уточнення протяжності твердого розчину на основі $\mathrm{Cu}_{2} \mathrm{SnSe}_{3}$ додатково синтезовано два зразки складу $97,5 \quad$ i $95 \% \quad \mathrm{Cu}_{2} \mathrm{SnSe}_{3}$. За результатами рентгенофазового аналізу, вони виявились однофазними, однак мікроструктура цих зразків показала присутність двох фаз: $\mathrm{Cu}_{2} \mathrm{SnSe}_{3}$ i $\mathrm{Sb}_{2} \mathrm{Se}_{3}$.

\section{3. Переріз $\mathrm{Cu}_{2} \mathrm{SnSe}_{3}-\mathrm{CuSbSe}_{2}$}

Для дослідження перерізу $\mathrm{Cu}_{2} \mathrm{SnSe}_{3}-\mathrm{CuSbSe}_{2}$ синтезовано 13 зразків описаним вище методом. За результатами дослідження побудовано діаграму фазових рівноваг (Рис. 3). Як видно з рисунка, переріз є квазіподвійною системою евтектичного типу з незначною розчинністю на основі вихідних компонентів. Координати евтектичної точки 93 мол.\% $\mathrm{CuSbSe}_{2}, 730 \mathrm{~K}$.

\section{4. Переріз $\mathrm{Cu}_{2} \mathrm{SnSe}_{3}-\mathrm{Cu}_{3} \mathrm{SbSe}_{3}$}

Переріз досліджувався на 13 зразках, синтезованих описаним вище методом. Розчинність на основі компонентів цього перерізу незначна, про що свідчить практична відсутність зміщення піків на дифрактограмах сплавів перерізу. Рентгенофазовий аналіз вказав на відсутність інших фаз, крім вихідних компонентів. Це свідчить про те, що в підсолідусній частині діаграми переріз $є$ квазіподвійною системою. Оскільки сполука $\mathrm{Cu}_{3} \mathrm{SbSe}_{3}$ утворюється (згідно 3 літературними відомостями) за перитектичною реакцією $\left(\mathrm{L}+\mathrm{Cu}_{2} \mathrm{Se} \leftrightarrow \mathrm{Cu}_{3} \mathrm{SbSe}_{3}\right)$, цей переріз не може бути рівноважною системою у надсолідусній області. Діаграма стану цього перерізу представлена на Рис. 4.

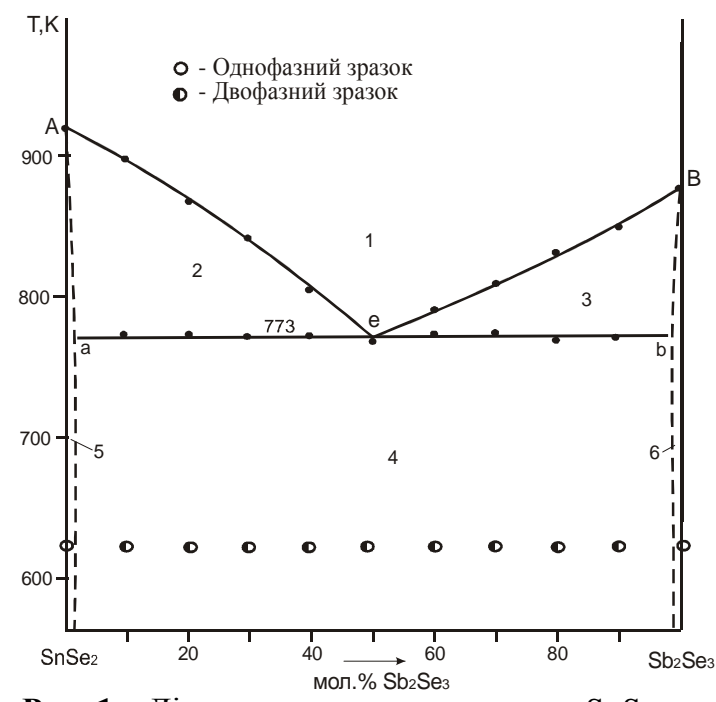

Рис. 1 Діаграма стану системи $\mathrm{SnSe}_{2}-$ $\mathrm{Sb}_{2} \mathrm{Se}_{3} .1-\mathrm{L} ; 2-\mathrm{L}+\alpha$-тв.p-н на основі $\mathrm{SnSe}_{2} ; 3$ - L + $\beta$-тв.p-н на основі $\mathrm{Sb}_{2} \mathrm{Se}_{3}$; 4 - $\alpha$-тв.p-н на основі $\mathrm{SnSe}_{2}+\beta$-тв.p-н на основі $\mathrm{Sb}_{2} \mathrm{Se}_{3} ; 5$ - $\alpha$-тв.p-н на основі $\mathrm{SnSe}_{2}$; 6 - $\beta$-тв.р-н на основі $\mathrm{Sb}_{2} \mathrm{Se}_{3}$.

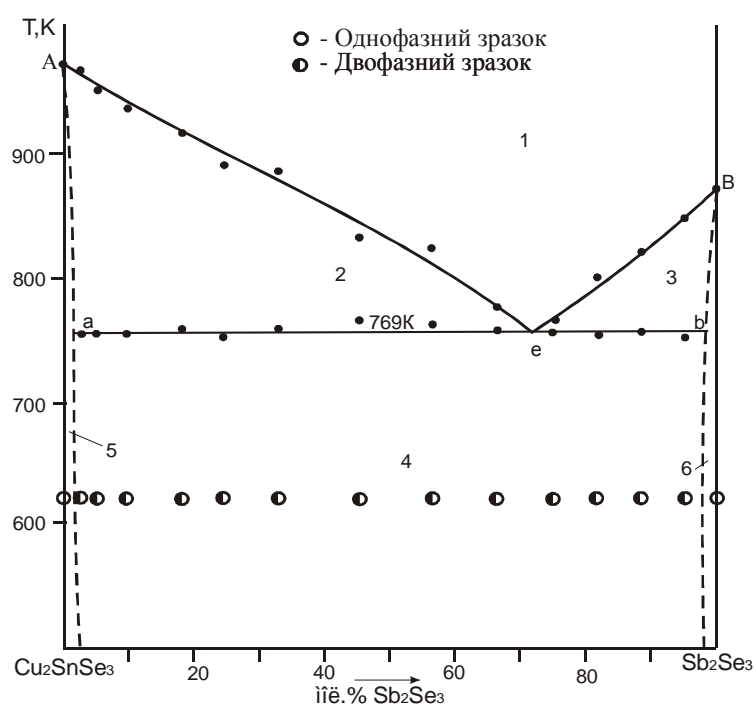

Рис. 2 Діаграма стану системи $\mathrm{Cu}_{2} \mathrm{SnSe}_{3}-$ $\mathrm{Sb}_{2} \mathrm{Se}_{3} .1-\mathrm{L} ; 2-\mathrm{L}+\alpha$-тв.p-н на основі $\mathrm{Cu}_{2} \mathrm{SnSe}_{3} ; 3-\mathrm{L}+\beta$-тв.p-н на основі $\mathrm{Sb}_{2} \mathrm{Se}_{3}$; $4-\alpha$-тв.р-н на основі $\mathrm{Cu}_{2} \mathrm{SnSe}_{3}+\beta$-тв.p-н на основі $\mathrm{Sb}_{2} \mathrm{Se}_{3} ; 5$ - $\alpha$-тв.p-н на основі $\mathrm{Cu}_{2} \mathrm{SnSe}_{3} ; 6$ - $\beta$-тв.p-н на основі $\mathrm{Sb}_{2} \mathrm{Se}_{3}$. 


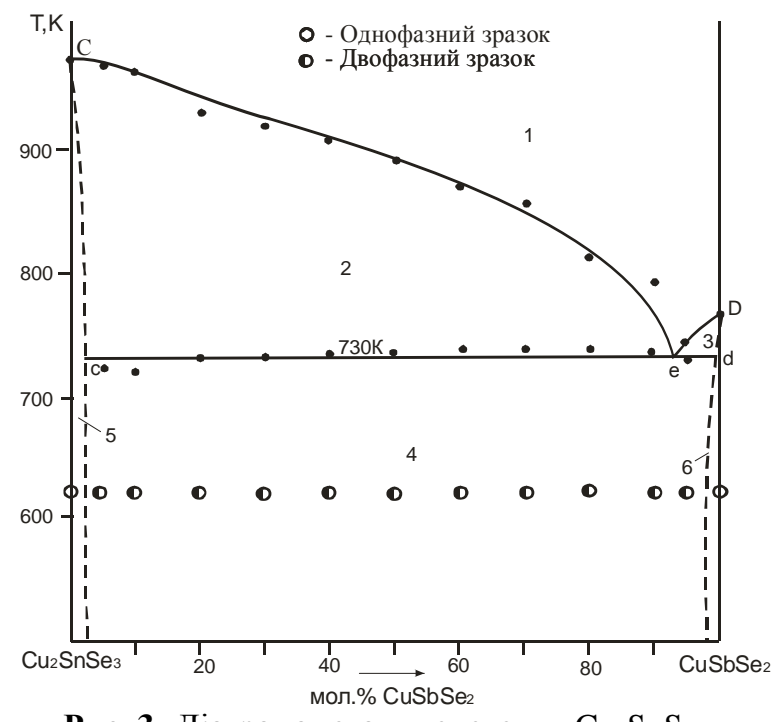

Рис. 3 Діаграма стану системи $\mathrm{Cu}_{2} \mathrm{SnSe}_{3}-$ $\mathrm{CuSbSe}_{2} .1-\mathrm{L} ; 2-\mathrm{L}+\alpha$-тв.p-н на основі $\mathrm{Cu}_{2} \mathrm{SnSe}_{3} ; 3-\mathrm{L}+\beta$-тв.p-н на основі $\mathrm{CuSbSe}_{2} ; 4$ - $\alpha$-тв.p-н на основі $\mathrm{Cu}_{2} \mathrm{SnSe}_{3}+$ $\beta$-тв.р-н на основі $\mathrm{CuSbSe}_{2} ; 5-\alpha$-тв.р-н на основі $\mathrm{Cu}_{2} \mathrm{SnSe}_{3} ; 6-\mathrm{L}+\beta$-тв.p-н на основі $\mathrm{CuSbSe}_{2}$

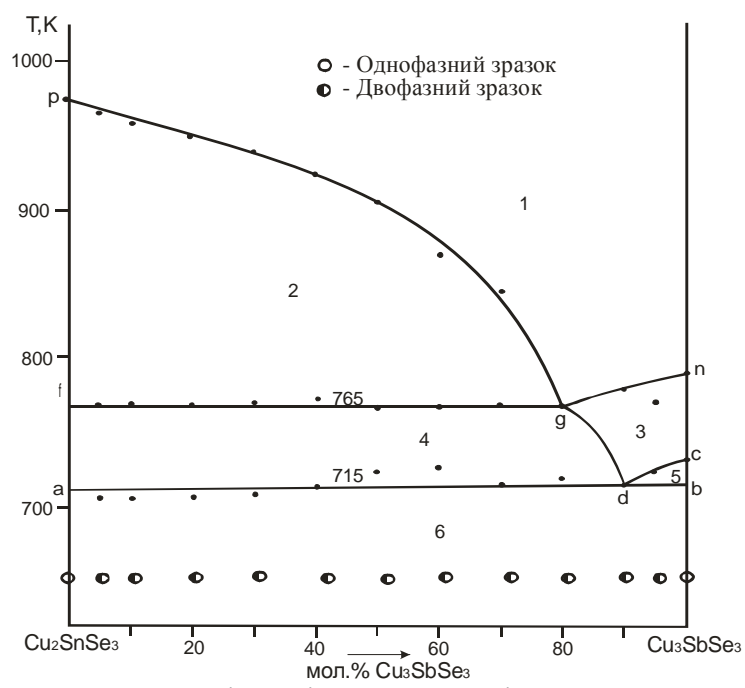

Рис. 4 Політермічний переріз $\mathrm{Cu}_{2} \mathrm{SnSe}_{3}-$ $\mathrm{Cu}_{3} \mathrm{SbSe}_{3} .1-\mathrm{L} ; 2-\mathrm{L}+\mathrm{Cu}_{2} \mathrm{SnSe}_{3} ; 3-\mathrm{L}+$ $\mathrm{Cu}_{2} \mathrm{Se} ; 4-\mathrm{L}+\mathrm{Cu}_{2} \mathrm{SnSe}_{3}+\mathrm{Cu}_{2} \mathrm{Se} ; 5-\mathrm{L}+$ $\mathrm{Cu}_{2} \mathrm{Se}+\mathrm{Cu}_{3} \mathrm{SbSe}_{3} ; 6-\mathrm{Cu}_{2} \mathrm{SnSe}_{3}+\mathrm{Cu}_{3} \mathrm{SbSe}_{3}$.

\section{5. Переріз $\mathrm{Cu}_{2} \mathrm{SnSe}_{3}-\ll \mathrm{SnSb}_{2} \mathrm{Se}_{5} »$}

Переріз досліджувався на 11 зразках, що синтезувались описаним вище методом. За результатами диференціального термічного та рентгенофазового аналізів побудовано діаграму фазових рівноваг цього перерізу (Рис. 5). Фазовий аналіз зразків дає підстави стверджувати, що однофазним є зразок, який містить $100 \% \mathrm{Cu}_{2} \mathrm{SnSe}_{3}$, двофазним є зразок, що відповідає складу $100 \%$ « $\mathrm{SnSb}_{2} \mathrm{Se}_{5} »\left(50 \% \mathrm{SnSe}_{2}+50 \% \mathrm{Sb}_{2} \mathrm{Se}_{3}\right)$, а решта зразків містять три фази $\left(\mathrm{Cu}_{2} \mathrm{SnSe}_{3}, \mathrm{SnSe}_{2}, \mathrm{Sb}_{2} \mathrm{Se}_{3}\right)$.
3.6. Переріз $\mathrm{CuSbSe}_{2}-\mathrm{SnSe}_{2}$

Для дослідження перерізу було синтезовано 11 зразків описаним вище методом. На дифрактограмах шести зразків присутні відбиття фаз $\mathrm{Cu}_{2} \mathrm{SnSe}_{3}, \mathrm{SnSe}_{2}$ i $\mathrm{Sb}_{2} \mathrm{Se}_{3}$, тоді як на трьох інших - $\mathrm{Cu}_{2} \mathrm{SnSe}_{3}, \mathrm{CuSbSe}_{2}$ i $\mathrm{Sb}_{2} \mathrm{Se}_{3}$. Це вказує на відсутність рівноваги між сполуками $\mathrm{CuSbSe}_{2}$ i $\mathrm{SnSe}_{2}$. Ліквідус перерізу (Рис. 6) обмежує поля первинної кристалізації фаз $\mathrm{CuSbSe}_{2}$ (крива ab), $\mathrm{Cu}_{2} \mathrm{SnSe}_{3}$ (криві br i rc) та $\mathrm{SnSe}_{2}$ (крива cd).

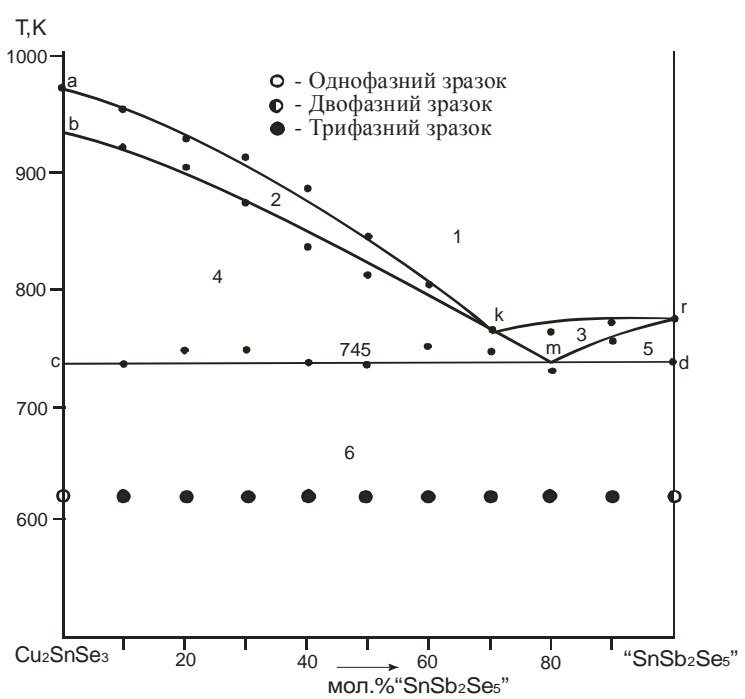

Рис. 5 Політермічний переріз $\mathrm{Cu}_{2} \mathrm{SnSe}_{3}-$ « $\mathrm{SnSb}_{2} \mathrm{Se}_{5} » .1-\mathrm{L} ; 2-\mathrm{L}+\mathrm{Cu}_{2} \mathrm{SnSe}_{3} ; 3-\mathrm{L}+$ $\mathrm{SnSe}_{2} ; 4-\mathrm{L}+\mathrm{Cu}_{2} \mathrm{SnSe}_{3}+\mathrm{SnSe}_{2} ; 5-\mathrm{L}+$ $\mathrm{SnSe}_{2}+\mathrm{Sb}_{2} \mathrm{Se}_{3} ; 6-\mathrm{L}+\mathrm{Cu}_{2} \mathrm{SnSe}_{3}+\mathrm{SnSe}_{2}+$ $\mathrm{Sb}_{2} \mathrm{Se}_{3}$.

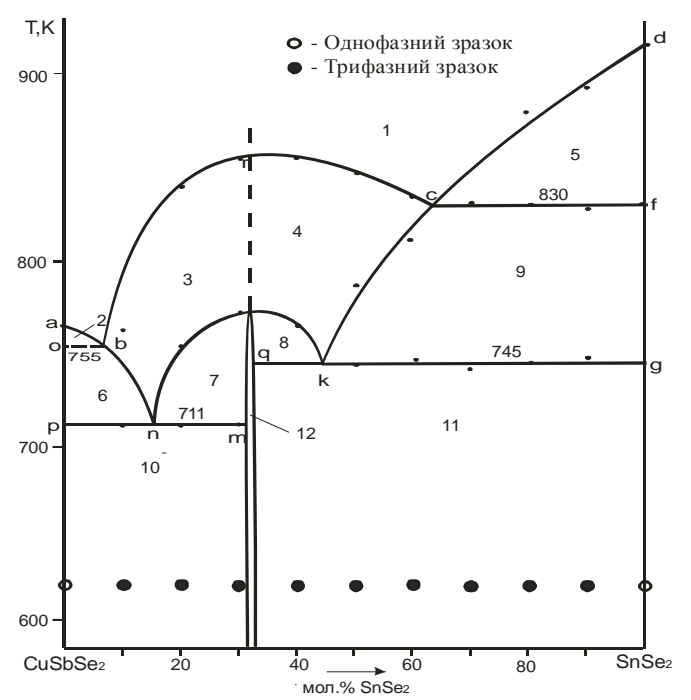

Рис. 6 Політермічний переріз $\mathrm{CuSbSe}_{2}-\mathrm{SnSe}_{2}$. $1-\mathrm{L} ; 2-\mathrm{L}+\mathrm{CuSbSe}_{2} ; 3,4-\mathrm{L}+\mathrm{Cu}_{2} \mathrm{SnSe}_{3}$; $5-\mathrm{L}+\mathrm{SnSe}_{2} ; 6-\mathrm{L}+\mathrm{Cu}_{2} \mathrm{SnSe}_{3}+\mathrm{CuSbSe}_{2}$; $7,8-\mathrm{L}+\mathrm{Cu}_{2} \mathrm{SnSe}_{3}+\mathrm{Sb}_{2} \mathrm{Se}_{3} ; 9-\mathrm{L}+\mathrm{Cu}_{2} \mathrm{SnSe}_{3}$ $+\mathrm{SnSe}_{2} ; 10-\mathrm{Cu}_{2} \mathrm{SnSe}_{3}+\mathrm{Sb}_{2} \mathrm{Se}_{3}+\mathrm{CuSbSe}_{2}$; $11-\mathrm{SnSe}_{2}+\mathrm{Sb}_{2} \mathrm{Se}_{3}+\mathrm{Cu}_{2} \mathrm{SnSe}_{3} ; 12-\mathrm{Sb}_{2} \mathrm{Se}_{3}+$ $\mathrm{Cu}_{2} \mathrm{SnSe}_{3}$. 
T.A. Ostapyuk et al., Phase equilibria in the quasiternary system $\mathrm{Cu}_{2} \mathrm{Se}-\mathrm{SnSe}_{2}-\mathrm{Sb}_{2} \mathrm{Se}_{3}$

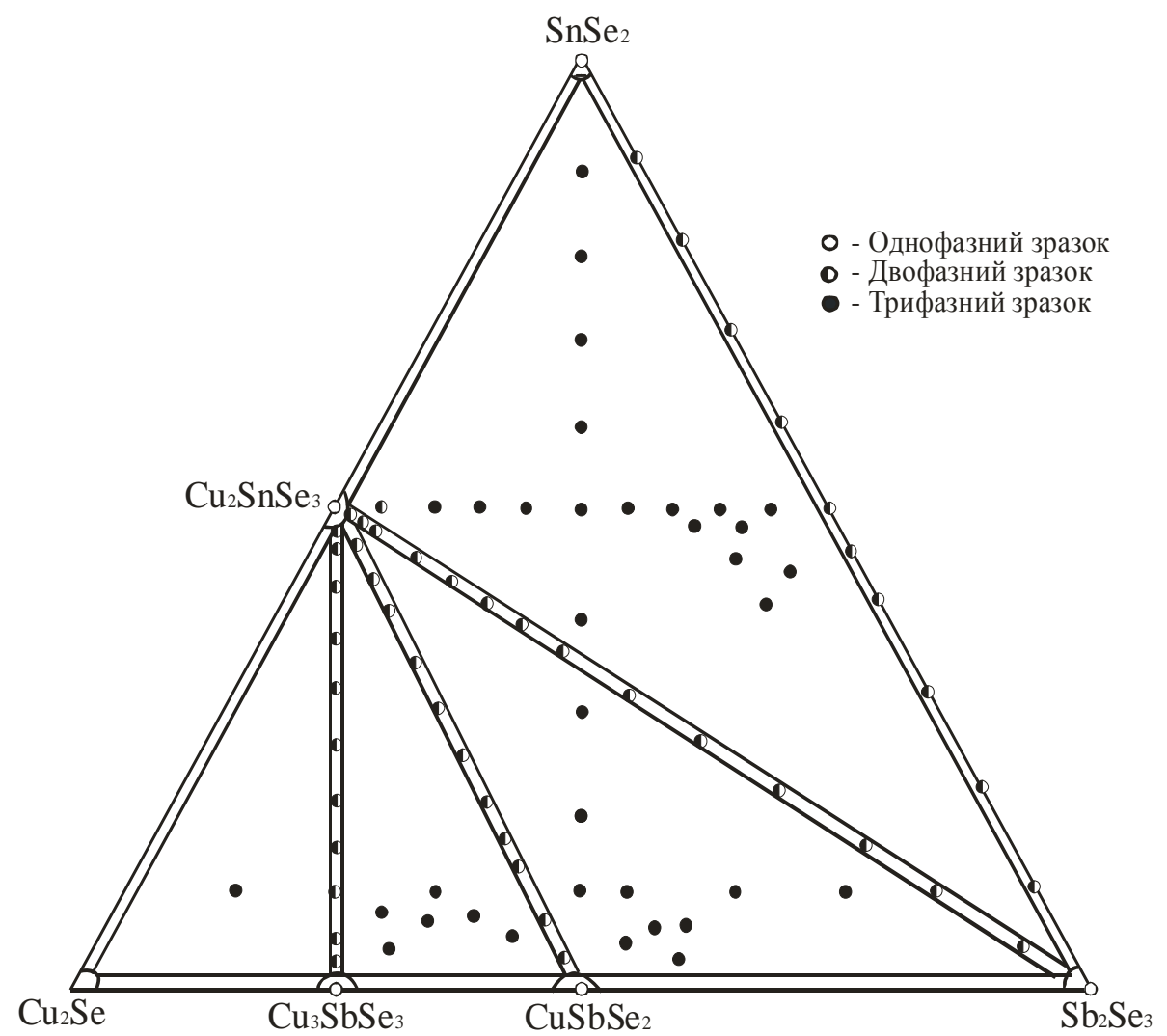

Рис. 7 Ізотермічний переріз діаграми стану системи $\mathrm{Cu}_{2} \mathrm{Se}-\mathrm{SnSe}_{2}-\mathrm{Sb}_{2} \mathrm{Se}_{3}$ при $620 \mathrm{~K}$.

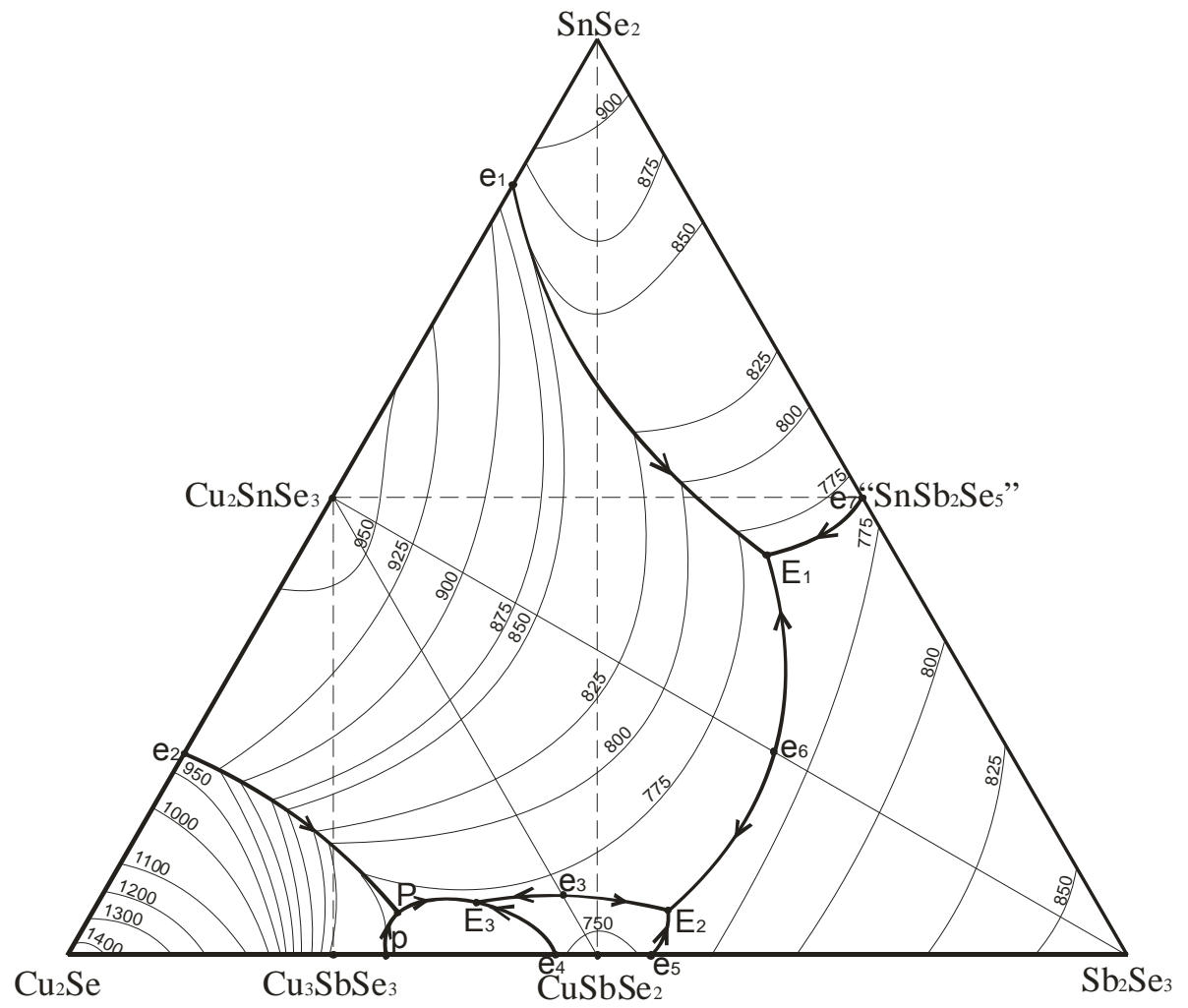

Рис. 8 Проекція поверхні ліквідусу квазіпотрійної системи $\mathrm{Cu}_{2} \mathrm{Se}-\mathrm{SnSe}_{2}-\mathrm{Sb}_{2} \mathrm{Se}_{3}$ на концентраційний трикутник. 
T.A. Ostapyuk et al., Phase equilibria in the quasiternary system $\mathrm{Cu}_{2} \mathrm{Se}-\mathrm{SnSe}_{2}-\mathrm{Sb}_{2} \mathrm{Se}_{3}$

Таблиця 1 Характер і температури перебігу моно- та нонваріантних процесів у квазіпотрійній системі $\mathrm{Cu}_{2} \mathrm{Se}-\mathrm{SnSe}_{2}-\mathrm{Sb}_{2} \mathrm{Se}_{3}$.

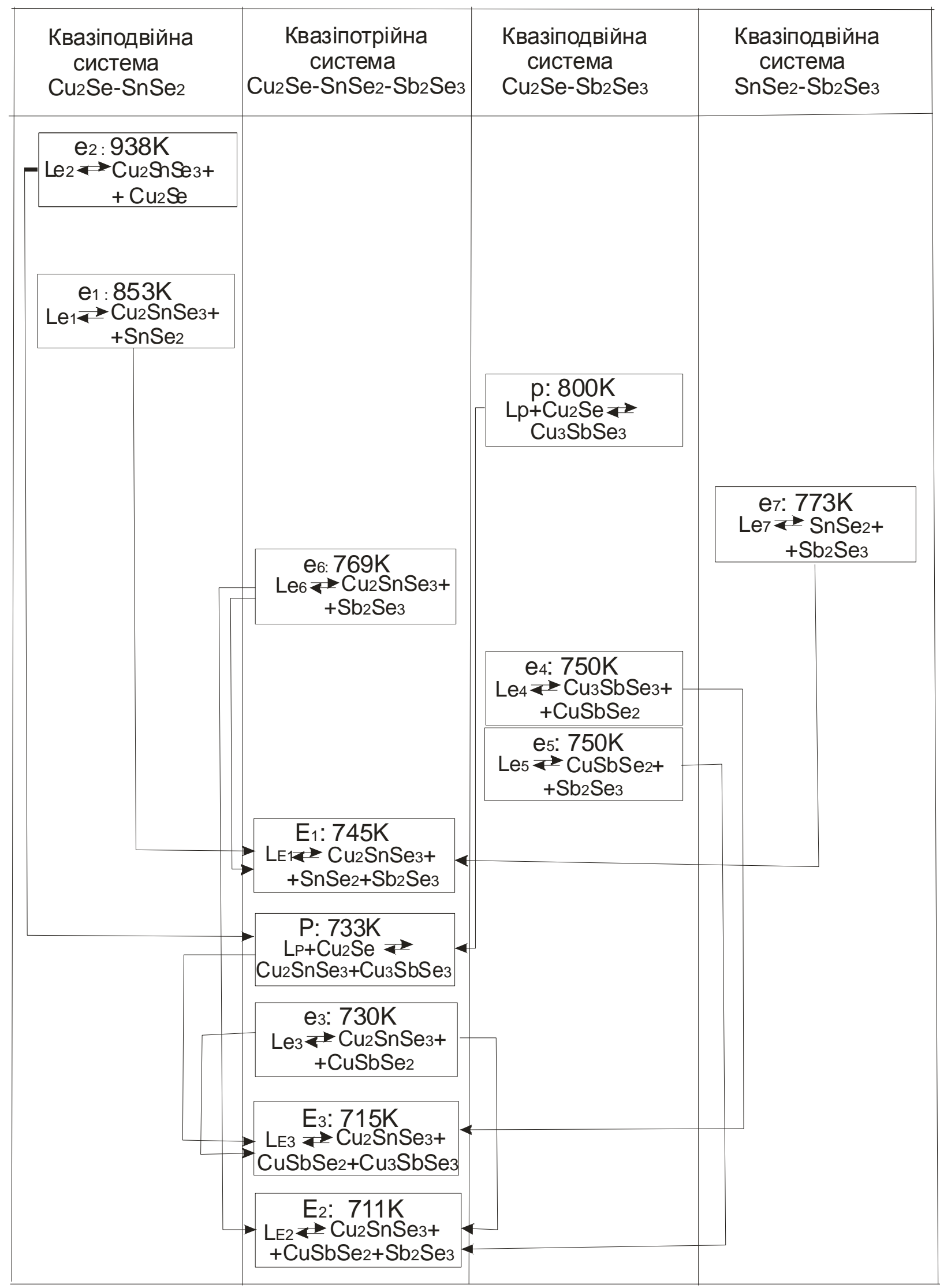


Поля 3, 7, 8, 9 є полями вторинної (сумісної) кристалізації фаз. Горизонталь pm відповідає початку третинної кристалізації $\mathrm{Cu}_{2} \mathrm{SnSe}_{3}+$ $\mathrm{CuSbSe}_{2}+\mathrm{Sb}_{2} \mathrm{Se}_{3}$, а горизонталь qg відповідає початку третинної кристалізації $\mathrm{Sb}_{2} \mathrm{Se}_{3}+\mathrm{Cu}_{2} \mathrm{SnSe}_{3}$ $+\mathrm{SnSe}_{2}$.

\section{7. Ізотермічний переріз системи $\mathrm{Cu}_{2} \mathrm{Se}_{-} \mathrm{SnSe}_{2}-$} $\mathrm{Sb}_{2} \mathrm{Se}_{3}$ при $620 \mathrm{~K}$

Результати дослідження 89 зразків методом рентгенофазового аналізу при $620 \mathrm{~K}$ дають можливість побудувати ізотермічний переріз діаграми фазових рівноваг системи $\mathrm{Cu}_{2} \mathrm{Se}-\mathrm{SnSe}_{2}-$ $\mathrm{Sb}_{2} \mathrm{Se}_{3}$ при цій температурі. Попередній аналіз термограм зразків показав, що при $620 \mathrm{~K}$ всі зразки перебувають у твердому стані. Тому саме ця температура була вибрана для гомогенізуючого відпалу. В системі не встановлено існування тетрарних фаз, а протяжність твердих розчинів на основі бінарних i тернарних сполук при температурі дослідження є мінімальною. Як видно 3 Рис. 7, при 620 К існують три подвійні рівноваги, які розділяють систему на 4 поля трифазних рівноваг: $\quad \mathrm{SnSe}_{2}-\mathrm{Sb}_{2} \mathrm{Se}_{3}-\mathrm{Cu}_{2} \mathrm{SnSe}_{3}, \quad \mathrm{Cu}_{2} \mathrm{SnSe}_{3}-$ $\mathrm{Sb}_{2} \mathrm{Se}_{3}-\mathrm{CuSbSe}_{2}, \quad \mathrm{Cu}_{2} \mathrm{SnSe}_{3}-\mathrm{CuSbSe}_{2}-\mathrm{Cu}_{3} \mathrm{SbSe}_{3}$, $\mathrm{Cu}_{2} \mathrm{SnSe}_{3}-\mathrm{Cu}_{3} \mathrm{SbSe}_{3}-\mathrm{Cu}_{2} \mathrm{Se}$.

\section{8. Проекція поверхні ліквідусу квазіпотрійної системи $\mathrm{Cu}_{2} \mathrm{Se}-\mathrm{SnSe}_{2}-\mathrm{Sb}_{2} \mathrm{Se}_{3}$}

На основі дослідження шести перерізів i літературних відомостей про взаємодію у квазіподвійних системах $\mathrm{Cu}_{2} \mathrm{Se}-\mathrm{SnSe}_{2}$ та $\mathrm{Cu}_{2} \mathrm{Se}-$ $\mathrm{Sb}_{2} \mathrm{Se}_{3}$ нами побудовано проекцію поверхні ліквідусу квазіпотрійної системи $\mathrm{Cu}_{2} \mathrm{Se}-\mathrm{SnSe}_{2}-$ $\mathrm{Sb}_{2} \mathrm{Se}_{3}$ на концентраційний трикутник (Рис. 8). Як видно з рисунка, поверхня ліквідусу складається 3 шести полів первинної кристалізації фаз $\mathrm{Cu}_{2} \mathrm{Se}$, $\mathrm{Cu}_{2} \mathrm{SnSe}_{3}, \quad \mathrm{SnSe}_{2}, \quad \mathrm{Sb}_{2} \mathrm{Se}_{3} \mathrm{CuSbSe}_{2}, \quad \mathrm{Cu}_{3} \mathrm{SbSe}_{3}$. Найбільшу площу займає поле первинної кристалізації тернарної сполуки $\mathrm{Cu}_{2} \mathrm{SnSe}_{3}$, яка є чотириелектронною, алмазоподібною [9] i, очевидно, найбільш термодинамічно стійкою. Поля первинної кристалізації розділені моноваріантними лініями, що перетинаються в нонваріантних точках. В Таблиці 1 наведені моноваріантні процеси (лініями та стрілками) і нонваріантні процеси (рівняння реакцій), що відбуваються у квазіпотрійній системі $\mathrm{Cu}_{2} \mathrm{Se}-$ $\mathrm{SnSe}_{2}-\mathrm{Sb}_{2} \mathrm{Se}_{3}$.

Квазіподвійні перерізи $\mathrm{Cu}_{2} \mathrm{SnSe}_{3}-\mathrm{Sb}_{2} \mathrm{Se}_{3}$ та $\mathrm{Cu}_{2} \mathrm{SnSe}_{3}-\mathrm{CuSbSe}_{2}$ (зображені суцільними лініями) триангулюють досліджувану систему на три підсистеми: $\quad \mathrm{Cu}_{2} \mathrm{SnSe}_{3}-\mathrm{Sb}_{2} \mathrm{Se}_{3}-\mathrm{SnSe}_{2}, \quad \mathrm{Cu}_{2} \mathrm{SnSe}_{3}-$ $\mathrm{Sb}_{2} \mathrm{Se}_{3}-\mathrm{CuSbSe}{ }_{2}, \mathrm{Cu}_{2} \mathrm{SnSe}_{3}-\mathrm{CuSbSe}_{2}-\mathrm{Cu}_{2} \mathrm{Se}$.

Тонкими кривими показані ізотерми кристалізації. Прямі суцільні та пунктирні лінії політермічні перерізи, які досліджувалися у цій системі.

\section{Література}

[1] В.М. Глазов, А.С. Пашинкин, В.А. Федоров, Неорг. матер. 35(7) (2000) 775-787.

[2] Н.X. Абрикосов, В.Ф. Банкина, Л.В. Порецкая, Е.В. Скуднова, С.Н. Чижевская, Полупроводниковые халькогениды и сплавы на их основе, М., Наука, 1975, 220 с.

[3] А.А. Бабицына, Т.А. Емильянова, М.А. Черницына, Ж. неорг. хим. 20(11) (1975) 3093-3096.

[4] Л.И. Бергер, Е.Г. Котина, Изв. АН СССР. Неорг. матер. 9(3) (1973) 368-370.

[5] Т.В. Зотова, Ю.А. Карагодин, Сборник Hаучных Работ по Проблемам Микроелектроники, М., МИЕТ, 1975, с. 59-61.

[6] I. Олексеюк, О. Парасюк, Л. Піскач, Г. Горгут, О. Змій, О. Криховець, Л. Сиса, Е. Кадикало, О. Строк, О. Марчук, В. Галка, Квазіпотрійні халькогенідні системи, Т. 1, Луцьк, Вежа, 1999, 168 с.

[7] М.И. Головей, В.И. Ткаченко, М.Ю. Риган, И.П. Стасюк, Неорг. матер. 26(5) (1990) $933-$ 934.

[8] Н.Б. Бабанлы, Автореф. дисс. ... канд. хим. наук, Баку, 1991, 23 с.

[9] Н.А. Горюнова, Сложные алмазоподобные полупроводники, М., Советское радио, 1968, $268 \mathrm{c}$. 